\title{
A SEDIMENTAÇÃO NA BAIA DE ARATU, BAHIA
}

\author{
ABILIO GARLOS DA SILVA PINTO BITTENCOURT*, \\ ARNO BRICHTA* e ENRICO DI NAPOLI*
}

\begin{abstract}
The bay of the Aratu is formed by four parts: the principal water body, the channel zone, the margins and the rivers'mouth. The sedimentation is mostly greyish-olive, silty-clay, containing few shell debris characterizing, in general, a weak energy sedimentary environment. In the margins and mouths of rivers the sediments are coarser and are constituted by fine sand and silt, always mixed with clay. In the narrower part of the channel the clay content $(10-30 \%)$ is smaller than in the other areas. Biogenic deposits are found mostly in shallow water, with predominant molluscs, some of which are considered to be relics.

Drilling data allowed the reconstruction of the Quaternary events in two parts: 1 - transgressive phase during the "Flandrian" (6.000-5.000 years) up to $2.83 \mathrm{~m}$ above the present mean sea level. It is characterized by bluish-grey, silty-clay sediments, with shell debris, reaching up to $30 \mathrm{~m}$. in thickness; in this phase there were developments of biogenic deposits related to climatic variations; 2 - regressive phase with continuous lowering until the present sea level with the rivers carrying coarse materials to their mouths.
\end{abstract}

INTRODUÇÃo No presente trabalho são expostos os resultados dos estudos sedimentológicos efetuados em amostras coletadas no fundo da Baía de Aratu. Como objetivo principal, visou-se à obtenção de um quadro detalhado da situação atual da distribuição, composição e textura dos sedimentos do fundo, constituindo-se este estudo na primeira tentativa de se conhecer a natureza do material do fundo da Baía de Aratu.

Mabesoone e Coutinho (1970) citam alguns dados de amostras coletadas pelo navio oceanográfico Calypso, na frente da Ilha da Maré e no interior da Baía de Aratu.

Por ocasião da implantação da área industrial na região de Aratu, um número aproximado de cem poços foram perfurados na baía, cujos perfis são apresentados sem comentários (Aratu, 1967).

Constitui-se numa pequena baía, com área aproximada de $20 \mathrm{~km}^{2}$, localizada no interior da Baía de Todos os Santos e a ela ligada por um canal estreito e profundo (Fig. 1). Ela assume uma grande importância no Estado da Bahia porque atualmente nessa área estão sendo instaladas diversas indústrias.

A baía apresenta um aspecto recortado com várias enseadas, sacos e pontas salientes. De maneira geral, de acordo com suas características fisiográficas, pode-se dividi-la em quatro partes: 1 - o que se denominou de "corpo principal" da baía, caracterizado por uma topografia de fundo razoavelmente plana extensa e por profundidades uniformes compreendidas entre 3 e $10 \mathrm{~m} ; 2$ - as enseadas e sacos com profundidades inferiores a $5 \mathrm{~m}$; 3 - as desembocaduras dos cursos de água; e 4 - o canal, estreito e profundo, que apresenta profundidades de até $50 \mathrm{~m}$.

Nas suas bordas, a Baía de Aratu apresenta um relevo mais ou menos acidentado, com morros atingindo, em média, cotas de $50 \mathrm{~m}$, podendo alcançar os $65 \mathrm{~m}$. A margem norte do canal apresenta declives mais abruptos que na margem sul, onde existem algumas planícies que se constituem em terraços, com cotas inferiores a $5 \mathrm{~m}$. Particularmente evidente é um grande terraço existente na zona da entrada do canal, na Ponta da Areia (Fig. 1), de origem marinha.

Uma característica da Baía de Aratu é a ausência de praias, com a total inexistência de estirâncios e bermas, ficando as suas margens essencialmente ocupadas por estreitos manguesais, com vegetação típica, incluindo arbustos, gramíneas marinhas e algas verdes macroscópicas, que se espalham por quase toda a borda da baía, notadamente nas partes

*Instituto de Geociências da Universidade Federal da Bahia 
mais protegidas, nas enseadas e sacos. Esses manguesais apresentam uma série de pequenos canais - gamboas (Kutner, 1962) - com percursos mais ou menos sinuosos, cuja alimentação depende basicamente das marés. Praias propriamente ditas são bem desenvolvidas na área externa à baía.

Uma série de coroas afloram na maré baixa, notadamente na zona do canal (enseada do Matoim, Fig. 1), correspondendo a terraços de erosão por efeito da ação das marés e pequenas ondas.

A movimentação topográfica circundante à baía é responsável pela existência dè numerosos córregos. Poucos rios de pequeno porte desenvolvem-se nas planícies.

O clima é do tipo tropical úmido com alta pluviosidade, com precipitações maiores de março a agosto. Os ventos são geralmente nordeste no verão e sudeste no inverno (vide anemograma, Fig. 1). A amplitude máxima das marés é de 2,80 m.

Medidas de salinidade realizadas por Peixinho (1972) nos meses de maiores e menores pluviosidades em três estações localizadas, respectivamente, no corpo principal, no canal e na área externa entre a entrada da baía e a Ilha da Maré, não mostraram variações significativas. $O$ valor máximo de salinidade, $36,9 \%$, foi observado no corpo principal durante o mês de fevereiro, com baixa precipitação, a uma profundidade de $2 \mathrm{~m}$; o mínimo, $29,6 \%$, no mesmo local, durante o mês de julho, com alta precipitação, na superficie.

Um total de 136 amostras foram coletadas com um amostrador de fundo tipo Van Veen segundo uma malha previamente estabelecida (Fig. 1). A amostragem foi estendida na área externa à baía até à Illha da Maré. As amostras foram processadas eliminando-se os sais solúveis por lavagem e filtração com água destilada e, a matéria orgânica, com $\mathrm{H}_{2} \mathrm{O}_{2}$ a 120 vol. As análises granulométricas foram feitas sem a eliminação do material carbonático, incluindo o peneiramento e a pipetagem. Foram construídas curvas granulométricas acumulativas em papel log-probabilístico e confeccionada uma série de mapas que expressam de preferência a distribuição textural dos sedimentos do fundo. Utilizando-se

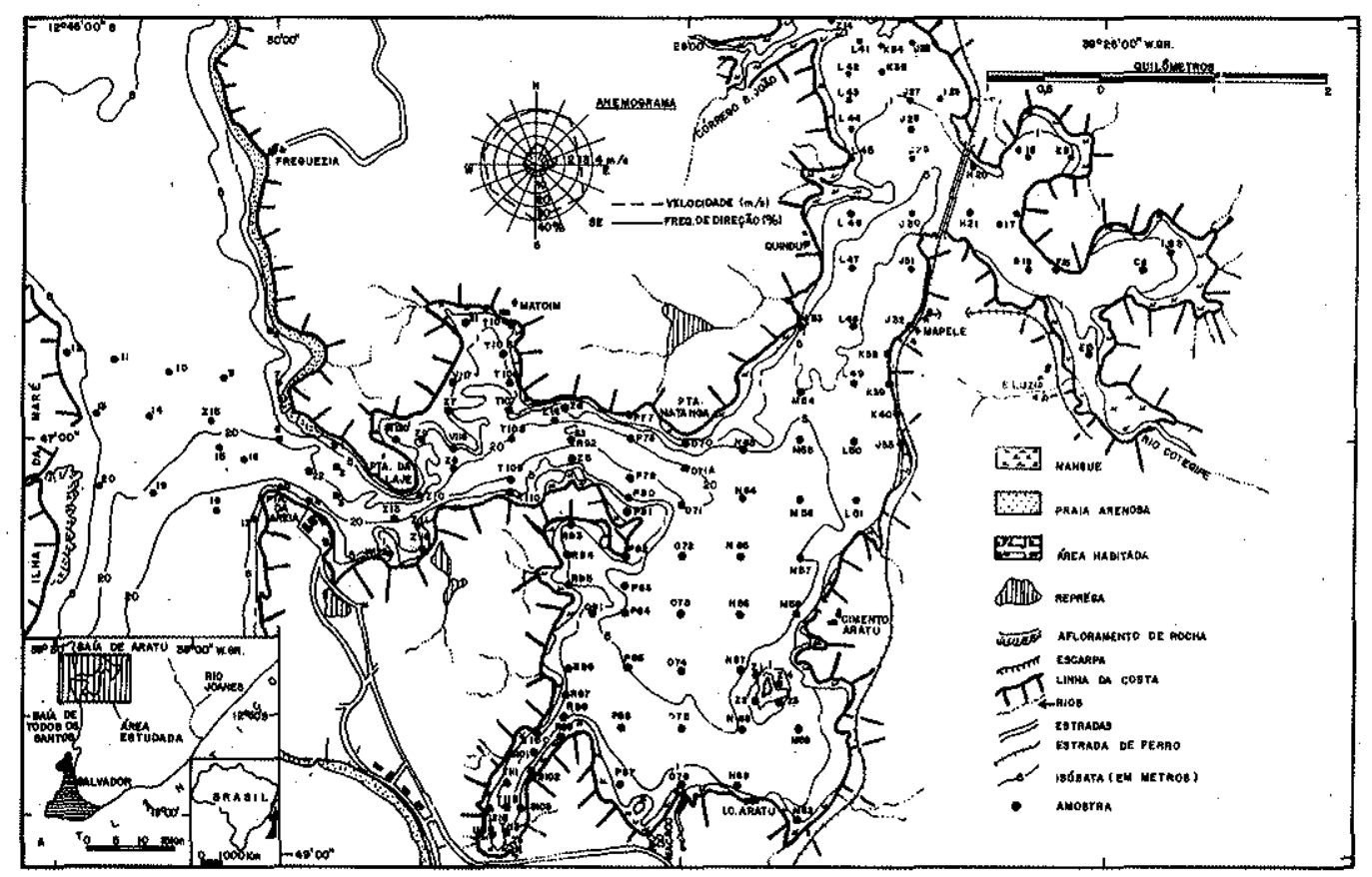

Figura 1 - Mapa fisiográfico e de localização das amostras 
todos os dados disponíveis, incluindo os de poços, foi feita uma tentativa de reconstituição da história geológica da Baía de Aratu, durante o Quaternário.

Proveniência e composiçăo dos sedimentos Os materiais do fundo da Báa de Aratu são originados em proporções variadas: 1 - dos cursos de água que adentram a baía; 2 - da erosão marginal provocada pelas correntes e pequenas ondas, notadamente no canal; 3 - da área externa à baía, trazidos pelo fluxo das marés; e 4- do escoamento superficial. A maior parte dos sedimentos deve provir dos cursos de água e do escoamento superficial.

A área que circunda a Baía de Aratu é constituída por sedimentos da Formação Ilhas, cretácea, caracterizados por duas diferentes fácies que ocupam áreas distintas (Aratu, 1967): uma, predominantemente argilosa e, outra, arenosa, respectivamente aflorantes a leste e a oeste de uma linha aproximadamente $\mathrm{N}-\mathrm{S}$, que passa pelo Rio do Macaco e Córrego São João (Fig. 1). A desagregação dessas rochas alimenta a rede de drenagem que, caracterizada por rios de pouca competência, só carrega praticamente materiais argilosos, notadamente nos períodos de maiores pluviosidades que, trazidos em suspensão, floculam em contato com a água salgada da baía, sedimentando-se.

Baseando-se em estudos feitos nas frações maiores que $62 \mu$ (Shepard e Moore, 1954), foram considerados, como constituintes fundamentais dos sedimentos de fundo da Baía de Aratu, quatro tipos de componentes, segundo a classificação de Emery $(1952,1968)$ : detríticos, biogênicos, autigênicos e relíquias. Os componentes detríticos predominam em quase toda a baía, incluindo a área externa. Alguns depósitos conchíferos (recentes e relíquias), onde os componentes biogênicos excedem os $50 \%$ da amostra, sobressaem-se na área. Os componentes autigênicos são encontrados sempre em porcentagens insignificantes. Foram considerados, ainda, como constituintes composicionais, a matéria orgânica e o oxigênio presentes na água.

Detríticos São representados pelos materiais terrígenos, predominantemente argilosos, na sua maioria com teores de argila superiores a $50 \%$ no total da amostra, notadamente no corpo principal da baía (Fig. 6). Na fração grosseira, o quartzo é dominante, seguido, em quantidades inferiores a $1 \%$, de mica e minerais opacos.

Biogênicos A composição e distribuição dos sedimentos biogênicos recentes do fundo da Baía de Aratu foram estudadas pelos Professores Enrico Di Napoli e Zelinda M. Nery Leão (comunicação pessoal). São representados por conchas e fragmentos esqueletais de diferentes organismos que cresceram no local onde são encontrados, ou muito próximo, e por restos de vegetais. Os principais restos de organismos encontrados, em ordem decrescente de importância, são: moluscos, Halimeda, equinodermas e foraminíferos, e, como constituintes menores, ostracodes, briozoários, cirrípedos, fragmentos de crustáceos, fragmentos de corais, tubos de vermes e espículas de esponjas. Teores de carbonatos medidos em 73 amostras distribuídas pelo corpo principal, pelo canal e pela área externa à baía, exprimindo a presença de conchas e fragmentos esqueletais no sedimento, estão representados na Fig. 2. Porcentagens superiores a $20 \%$ (média de $42 \%$ ), com alguns locais ultrapassando os $50 \%$, estão restritas às bordas da baía e da área externa, e a algumas manchas no fundo do canal. O restante da área apresenta um teor médio de $12 \%$ (máximo, $20 \%$, mínimo, $3 \%$ ). Restos de vegetais aparecem em muitas amostras, com maiores concentrações na desembocadura dos cursos de água e nos manguesais. Na frente de um riacho próximo ao Rio do Macaco (Fig. 1) essa porcentagem atinge $40 \%$ da fração grosseira. Shepard e Moore (1955) observam que essa concentração de restos de plantas parece ser um bom critério para indicar a proximidade de bocas de rio. 


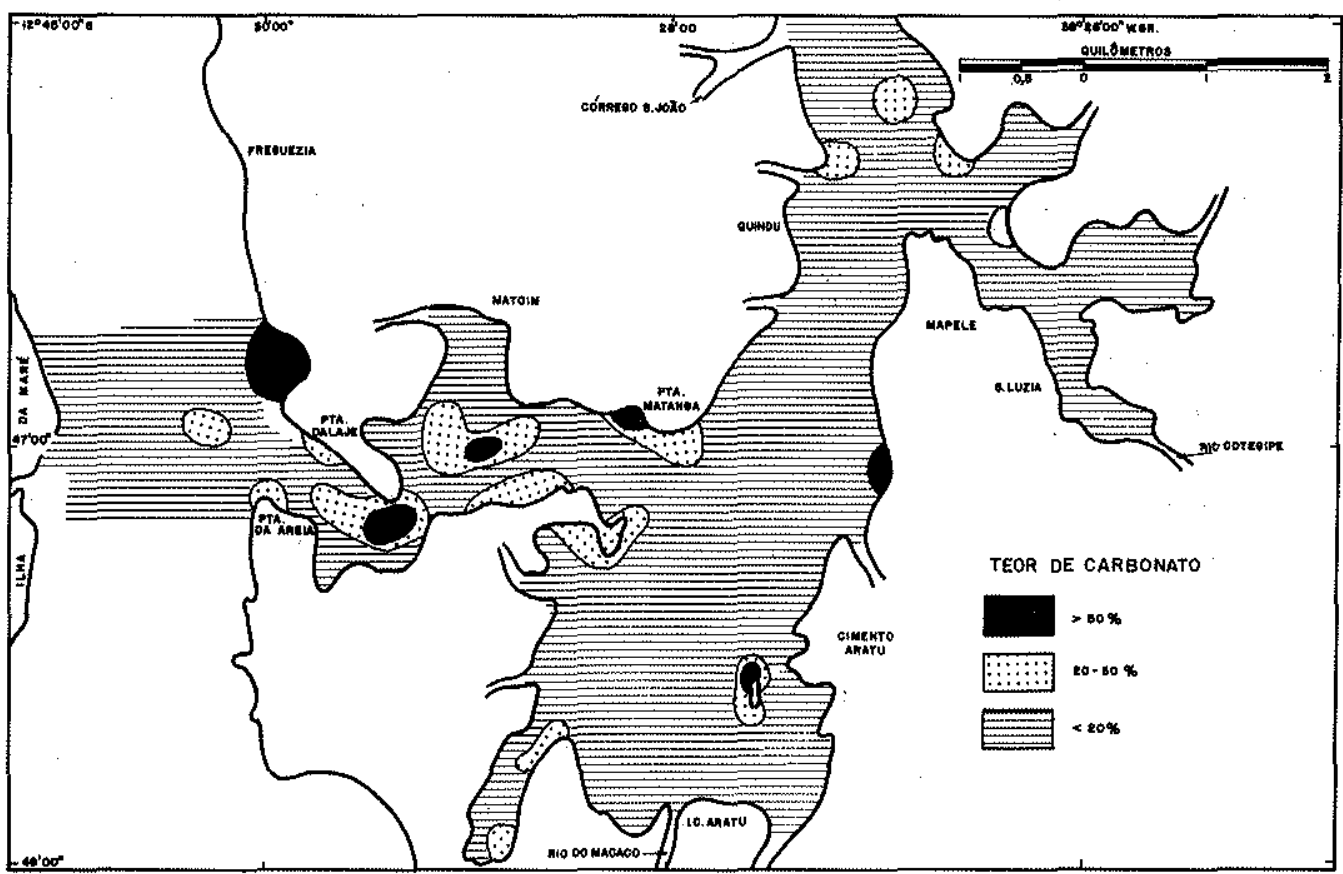

Figura 2 - Distribuição dos teores de carbonato, em peso

Autigênicos São representados por chamosita, goetita e siderita. A chamosita é encontrada na forma de preenchimentos e moldes internos de alga Halimeda, gasterópodos e foraminíferos, como também na forma de pelotas fecais, com porcentagens em peso, na fração grosseira, variando entre $0,01 \%$ e $6 \%$. As amostras com chamosita estão concentradas na zona do canal e na área externa à baía, com profundidades variando entre $5 \mathrm{~m}$ e $30 \mathrm{~m}$ (Bittencourt, et al.). Segundo esses autores, "a chamosita, na forma de preenchimento, indica claramente uma origem diagenética pós-deposicional, com condições locais redutoras" (dentro da própria pelota fecal ou carapaça de foraminífero, por exemplo). A goetita, na forma de pequenos grãos arredondados, foi encontrada (Bittencourt et al.) em porcentagens insignificantes em três amostras, sendo, duas delas, próximas às desembocaduras do Rio Cotegipe e do Córrego São João. Porrenga (1967) considera poderem as pelotas de goetita constituir-se nos produtos de oxidação de grãos retrabalhados de chamosita. A siderita é citada por Bittencourt et al., como sendo encontrada na forma de pequeninos cristais encrustando fragmentos de conchas, na desembocadura do Córrego Șão João. Sellwood (1971) considera que o suprimento de ferro para a formação da siderita pode ser derivado de fontes terrígenas, onde o ferro deve existir em quantidades disponíveis para produzir uma variedade de minerais de ferro: o ferro viria na forma de óxidos, como filmes, sobre plaquetas de argila trazidas pelos rios. Condições de formação são discutidas por Sellwood (1971):

Relíquia Remanescentes de um ambiente mais antigo (Pleistoceno) são considerados pelos Professores Enrico Di Napoli e Zelinda M. Leão (comunicação pessoạl) como estando representados por acumulações de componentes biogênicos, onde predominam fragmentos grosseiros de moluscos, em dois diferentes locais situados nas zonas profundas do canal e da área externa à baía (amostras Z13 e Z15, Figs. 1 e 2). Os fragmentos de Halimeda, subordinados, apresentam os poros e canalículos preenchidos por material argiloso e/ou chamosita enquanto que as conchas de moluscos se apresentam esburacadas e desgastadas, provavelmente por solução, em épocas que estiverem talvez submetidas a condições de 
pH ácido. Emery (1965) e Swift (1970) consideram ser esses buracos por solução uma característica de sedimento relíquia, adquirida durante intemperismo no Pleistoceno. A associação desse material com a chamosita reforça sua relação com antigos ambientes do Quaternário (Bittencourt $e t$ al.). Considerações geológicas, que serão discutidas adiante, parecem indicar que parte dos depósitos conchíferos aflorantes nas bordas trata-se de material relíquia.

Teor de matéria orgânica Os teores de matéria orgânica nos sedimentos do fundo da Baía de Aratu, expressos pela Fig. 3, são representados pela perda em peso após o ataque com $\mathrm{H}_{2} \mathrm{O}_{2}$. A matéria orgânica é derivada principalmente de plantas dos manguesais e algas sésseis, e de organismos plantônicos e bentônicos. De uma maneira geral, a maior parte dos sedimentos do fundo da Baía de Aratu apresenta porcentagens entre $1 \%$ e $3 \%$. Localmente, nos manguesais e na frente dos cursos de água, esses teores crescem, podendo exceder os $5 \%$, sendo a vegetação dos manguesais a principal fonte de matéria orgânica. Os depósitos de componentes relíquia apresentam baixos teores de matéria orgânica $(<1 \%)$, indicando que se trata de organismos já mortos. De um modo geral, as acumulações de componentes biogênicos não próximos às regiões dos manguesais apresentam, também, baixas porcentagens de matéria orgânica.

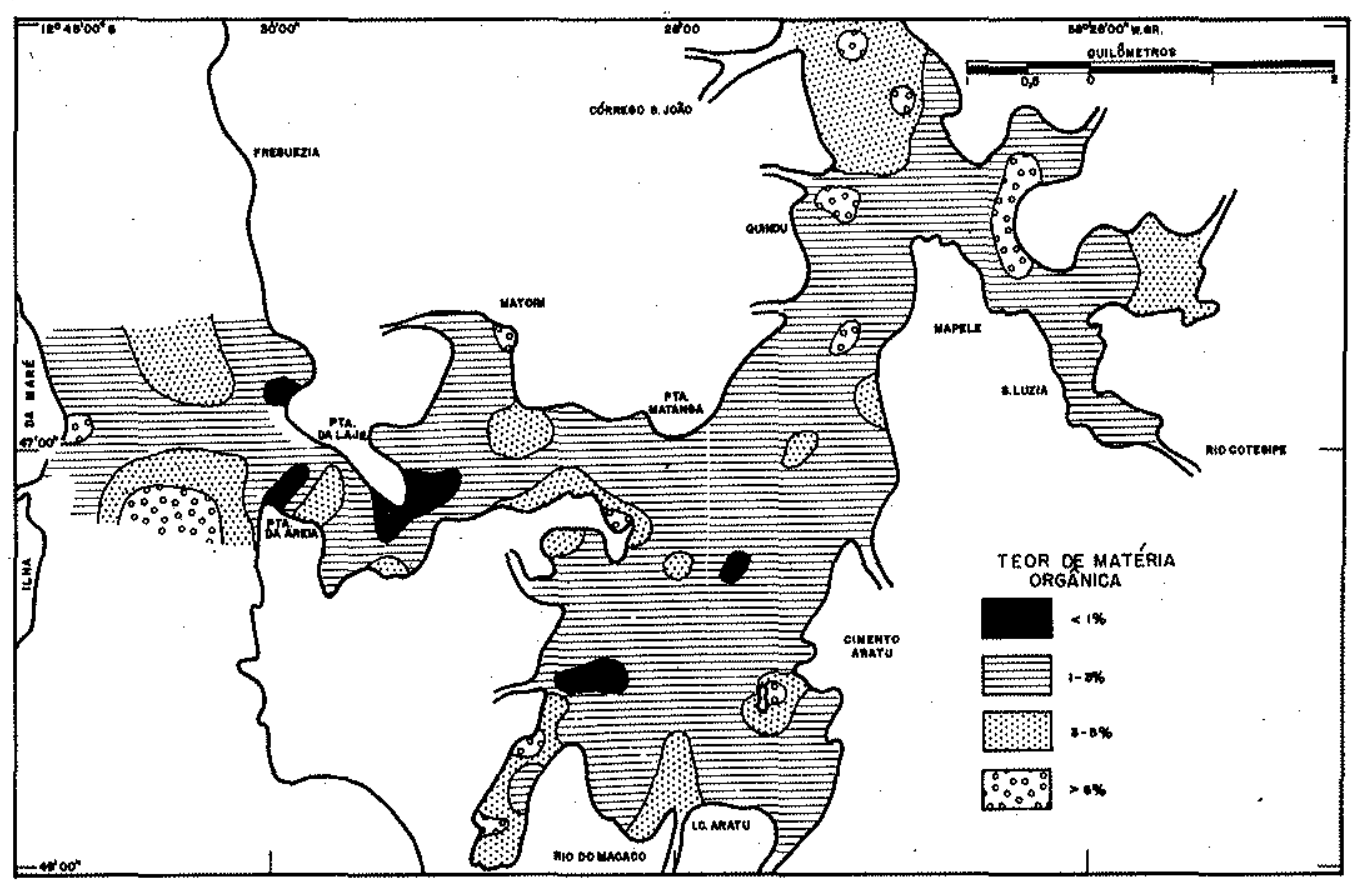

Figura 3 - Distribuição dos teores de matéria orgânica, em peso

Teor de oxigênio Na Baía de Aratu, Peixinho (1972) encontrou teores de oxigênio dissolvidos na água com valores mínimo de 2,70 e máximo de $5,61 \mathrm{ml} / \mathrm{l}$. Esses teores são suficientemente elevados para manter e desenvolver todas as formas de vida da baía. Segundo Emery e Stevenson (1957), a quantidade mínima de oxigênio adequada para a respiração normal de muitos animais marinhos parece ser de 1,0 ou $2,0 \mathrm{ml} / \mathrm{l}$.

$\mathrm{Na}$ tentativa de se enquadrar os sedimentos de fundo da Baía de Aratu, conforme a classificação apresentada por Mabesoone (1971) para os sedimentos da plataforma con- 
tinental brasileira, observa-se que quase toda a baía apresenta sedimentos da "fácies de lama" com menos de $20 \%$ de biodetritos (Figs. 2 e 6). Localmente, os depósitos biogênicos perfazem mais de $50 \%$ do total da amostra constituindo-se na "fácies biodetrítica". Na frente dos rios do Macaco e Cotegipe existem manchas da "fácies de areia quartzosa" com pouca argila.

Aspectos texturais TIPOS TEXTURAIS E SUA DISTRIBUIÇÃO As porcentagens dos diferentes tipos texturais em termos de areia, silte e argila estão representadas no triângulo de Shepard (1954) e em mapa (Fig. 4). Na fração granulométrica areia estão inclusas conchas e fragmentos esqueletais, cujos tamanhos podem ultrapassar os $8 \mathrm{~mm}$. De uma maneira geral, quase toda a baía, incluindo a área externa defronte à Itha da Maré é constituída de material tipo argilo-siltoso. No corpo principal notam-se áreas nitidamente argilosas. $\mathrm{O}$ material do tipo silte-argiloso aparece predominantemente nas bordas da baía, em pequenas manchas. Os materiais granulometricamente mais grosseiros ou estão ligados a acumulações de conchas (Figs. 2 e 4) ou estão localizados na desembocadura dos cursos de água, quando são representados por material quartzoso.

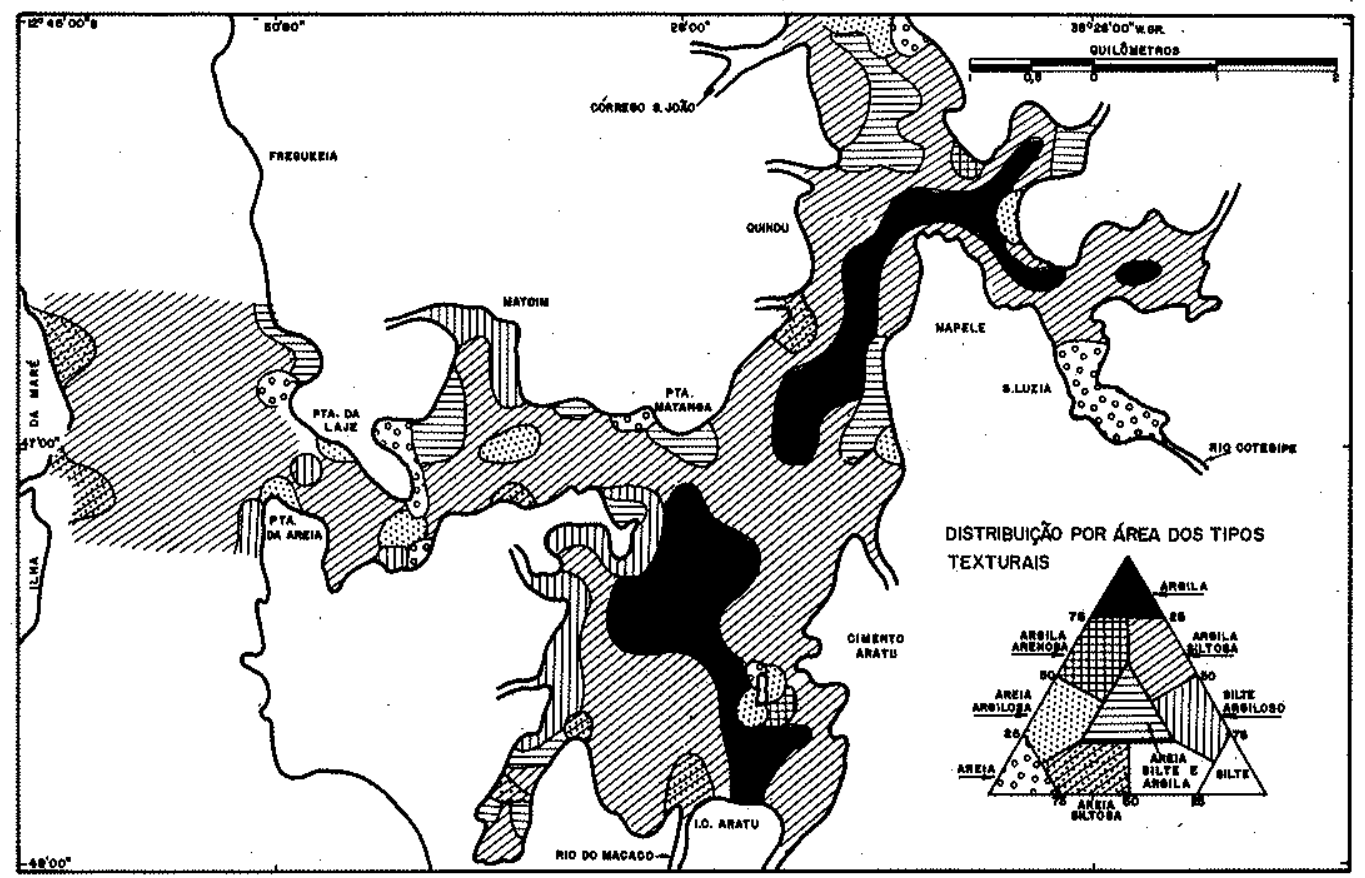

Figura 4 - Mapa representando o triângulo de Shepard e a distribuição dos diferentes tipos texturais

GURVAS GRANULOMÉTRICAS Inicialmente, tentou-se agrupar as curvas granulométricas segundo a posição que a amostra ocupava no diagrama textural de Shepard (1954). Observou-se, entretanto, que as conchas presentes nos sedimentos mais grosseiros descaracterizavam as curvas, eliminando a possibilidade de reuni-las em grupos homogêneos expressivos dos diferentes depósitos. Tendo em vista essa dificuldade procurou-se, por tentativas, reuni-las conforme seus andamentos similares, resultando uma diferenciação em três grupos, denominados de grupos I, II e III. Assim, ainda por tentativa, foi construído um mapa representando a distribuição desses grupos de curvas na área (Fig. 5). 


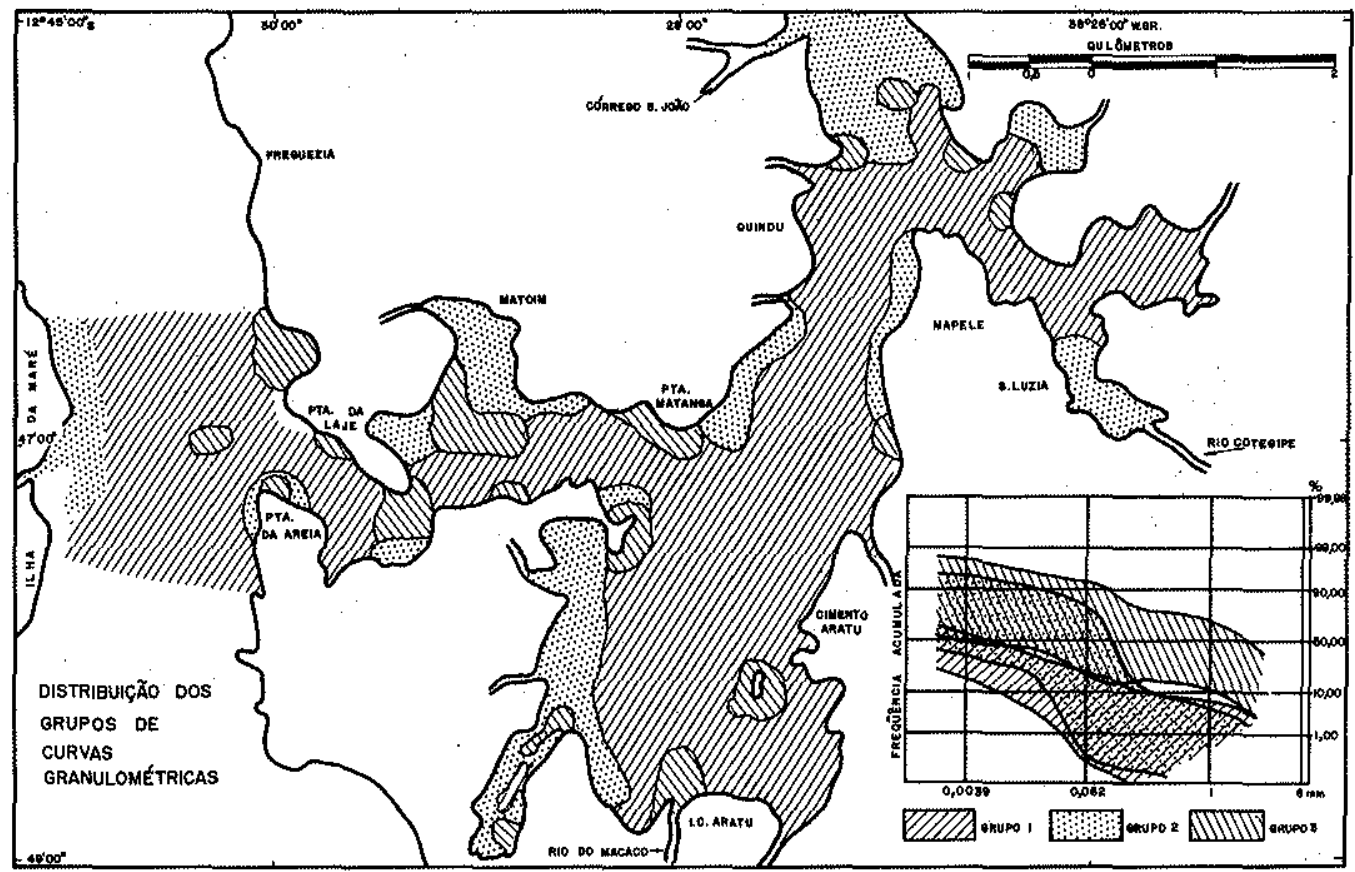

Figura 5 - Mapa representando os diferentes grupos de curvas granulométricas e as suas distribuições

O grupo I, correspondendo na quase totalidade às áreas dos tipos texturais argila-siltosa e argila da Fig. 4, é constituído de amostras com porcentagens de argila variando entre $45 \%$ e $83 \%$, material transportado por suspensão gradada (saltação), em mistura com pouco ou quase nenhum material grosseiro. $\mathrm{O}$ grupo II, restrito às bordas da baía $\mathrm{e}$ à desembocadura dos cursos de água, apresenta porcentagens de argila entre $5 \%$ e $65 \%-$ é notável neste grupo a presença de uma população de areia fina a silte grosseiro, relativamente bem selecionada, típica de transporte por saltação. Por fim, o grupo III, com teores de argila entre $2 \%$ e $50 \%$, é tipicamente representativo dos sedimentos com mais de $20 \%$ de conchas e fragmentos esqueletais (Figs. 2 e 5), com exceção da amostra na frente do Rio do Macaco, que é constituída de grãos de quartzo. As curvas dos grupos I e III, com andamentos similares e baixos selecionamentos, não apresentam uma evidente separação entre as populações por rolamento, saltação e suspensão, diferenciando-se unicamente pelos teores de argila, que decrescem do grupo I para o grupo III e pela fração grosseira que, inversamente, aumenta de tamanho e de porcentagem do grupo I para o grupo III.

A população por saltação nesses dois últimos grupos ou é ausente ou, quando prem sente, mal selecionada, com porcentagens reduzidas: Efetivamente, constata-se que os três grupos de curvas caracterizam três diferentes tipos de depósitos: o material argilo-siltoso do fundo, o material conchífero e os materiais siltico-arenosos das bordas e desembocaduras dos cursos de água.

TEOR DE ARGILA Os diferentes teores de argila $(<4 \mu)$ dos sedimentos do fundo da Baía de Aratu estão representados na Fig. 6. No corpo principal da baía predominam porcentagens maiores que $70 \%$, que vão decrescendo para as bordas. $\mathrm{Na}$ zona do canal e na parte externa à baía, os teores são menores que no corpo principal. Na parte mais 


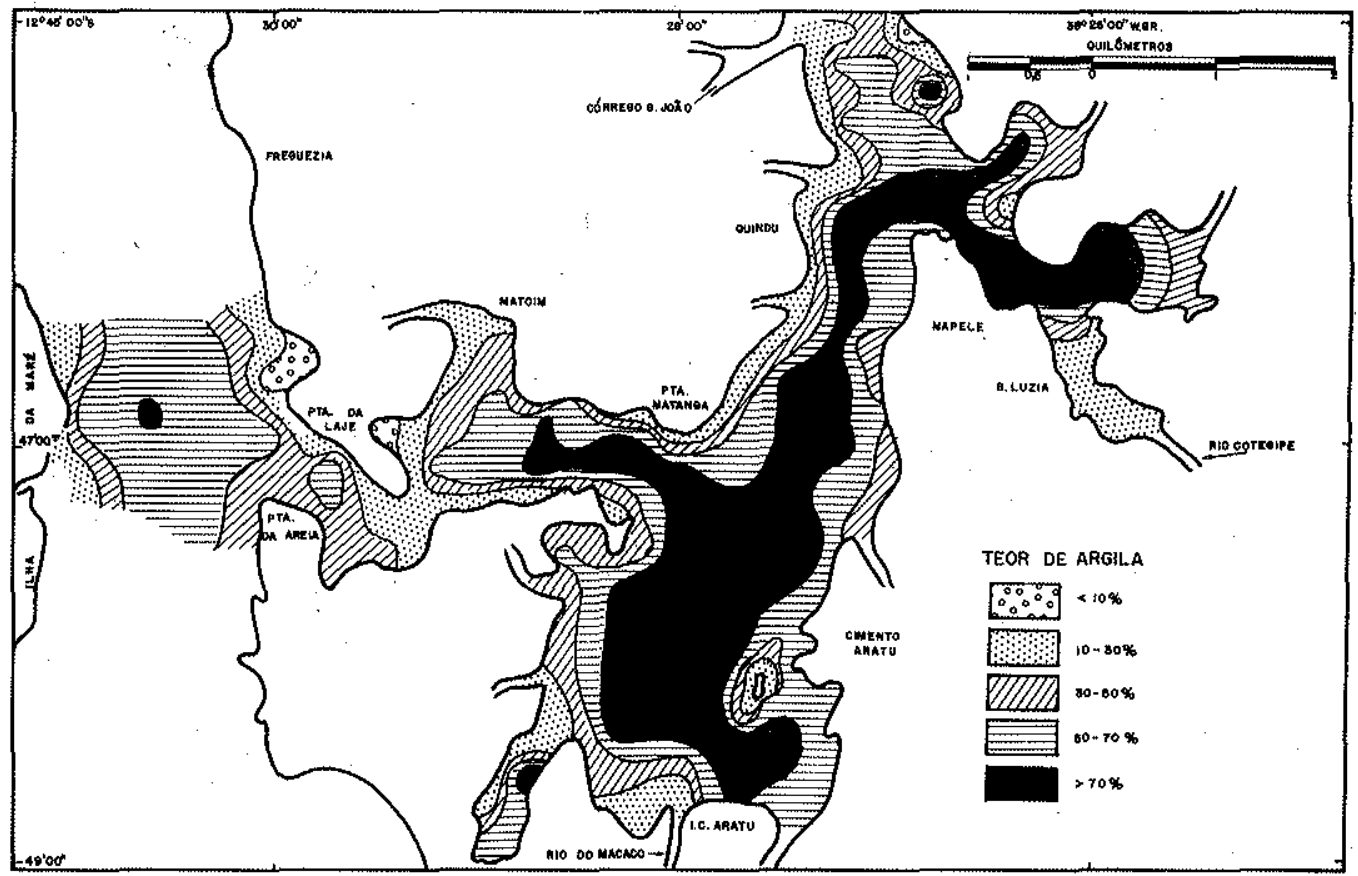

Figura 6 - Distribuição dos teores de argila

estreita do canal (Ponta da Laje), as porcentagens são menores que 30\%. Nas desembocaduras dos rios do Macaco e Cotegipe, os teores são inferiores a $30 \%$, sendo maiores à frente do córrego São João, entre $30 \%$ e $50 \%$.

MEDIANA O mapa de distribuição dos valores da mediana (Fig. 7) apresenta um padrão bem semelhante ao mapa da argila (Fig. 6), evidenciando estar a mesma estreitamente influenciada pela porcentagem de argila no sedimento. A quase totalidade das amostras tem valores baixos, menores que $62 \mu$. $\mathrm{O}$ corpo principal e a parte externa à baía apresentam medianas inferiores a $4 \mu$; valores mais altos, entre 4-16 e 16-62 $\mu$, são encontrados nas bordas da baía e na maior parte do canal. Valores maịores que $62 \mu$ são espalhados e limitados aos depósitos biogênicos (até $2450 \mu$, amostra $\mathrm{P} 77$ ) e à frente dos cursos de água.

DISTRIBUIÇÃO DO MATERIAL GROSSEIRO Passega, Rizzini e Borghetti (1967), estudando os sedimentos de fundo da plataforma continental do Mar Adriático, apresentaram um mapa de distribuição do "G" (percentil de $1 \%$ ), que expressa os diâmetros dos materiais mais grosseiros presentes no sedimento. Na Baía de Aratu, esse tipo de mapa (Fig. 8) resultou expressivo pelo fato de salientar marcadamente, com valores do " $\mathrm{C}$ " maiores que $1000 \mu$, à semelhança das curvas granulométricas do grupo III (Fig. 5), os sedimentos com mais de $20 \%$ de conchas. As únicas exceções restringem-se às duas manchas na desembocadura dos rios do Macaco e Cotegipe, representadas por material quartzoso. Este material terrígeno pode ser bem separado no confronto entre as Figs. 2 e 8 , quando os materiais com elevados valores do "C", na frente dos rios, apresentam baixos teores de carbonato.

GOLORAÇÃO DOS SEDIMENTOS A coloração dos sedimentos do fundo da Baía de Aratu foi anotada na amostra seca. Com exceção das amostras na frente dos rios do 


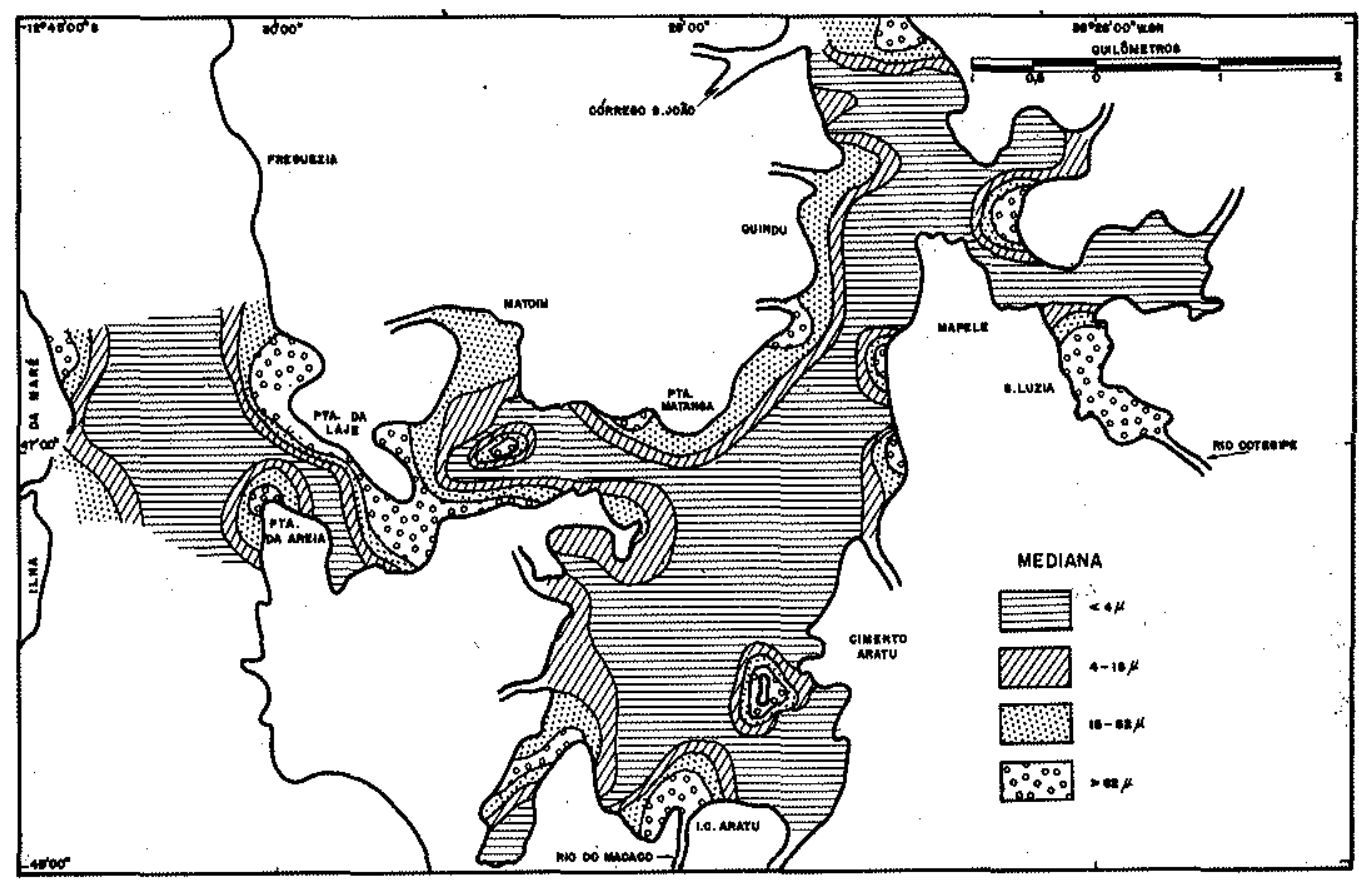

Figura 7 - Mapa de distribuiçăo dos valores da mediana

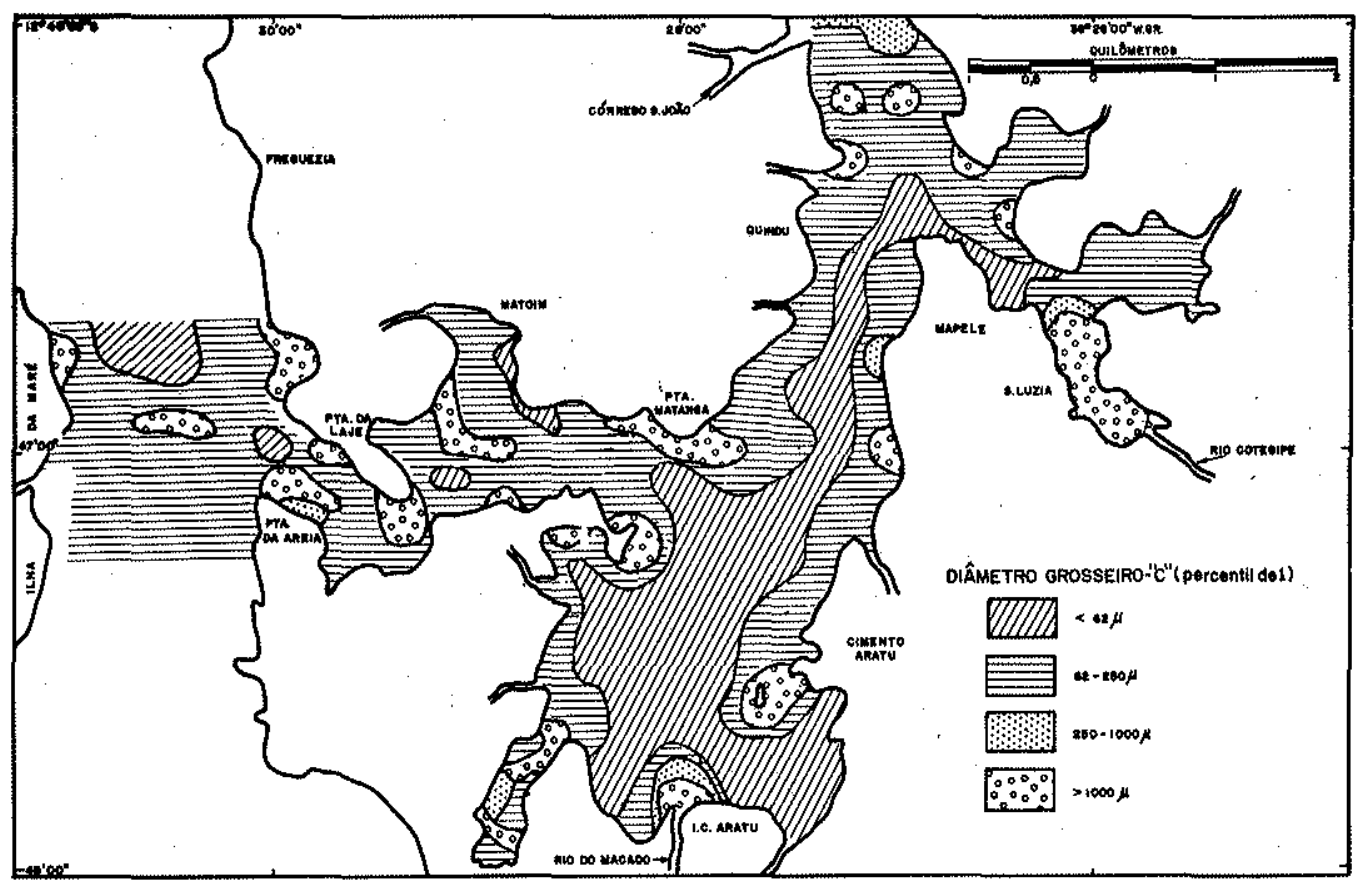

Figura 8 - Mapa representando a distribuição do " $\mathrm{C}$ ", correspondendo aos diâmetros mais grosseiros presentes nos sedimentos 
Macaco e Cotegipe e do Córrego São João, que apresentam colorações marrons, todas as demais são de coloração oliva-acinzentada. Essa predominância está relacionada, como é observado por Marlowe (1968) nos sedimentos de Baffin Bay, com a presença de matéria orgânica e de compostos ferrosos, correspondendo a condições redutoras no fundo. As amostras com colorações marrons, na frente dos rios, devem resultar da oxidação de minerais de ferro - presença de goetita e de grãos de quartzo com filmes de óxido de ferro.

DADOS DOS POÇOS Os poços perfurados na Baía de Aratu (Aratu, 1967) estão localizados no corpo principal, nas enseadas do Matoim, do Córrego São João e do Rio Cotegipe e nas proximidades da Fábrica de Cimento Aratu e da pequena ilha defronte. Os poços, alcançando sempre a Formação Ilhas, foram perfurados unicamente em águas rașas - máximo de $5 \mathrm{~m}$ de lâmina de água.

As perfurações feitas em locais próximos às bordas, com lâminas de água de até $1 \mathrm{~m}$ apresentam ou depósitos conchíferos ou areia fina siltosa, cinza, com fragmentos de vegetais. Os depósitos conchíferos se estendem, acompanhando a topografia, até uma profundidade de $10 \mathrm{~m}$, sendo sempre cobertos por um material argilo-siltoso, cinza-azulado. Alguns desses depósitos afloram na superfície, sendo que em vários perfis feitos entre a Fábrica de Cimento Aratu e a ilha defronte mostram uma continuidade na superficie até uma cota de 2,83 $\mathrm{m}$ acima do nível médio do mar, misturados com argila azulada contendo fragmentos de conchas. Nas planícies marginais do Córrego São João e do Rio Cotegipe são encontrados materiais argilosos cinza-azulados, moles, com poucos fragmentos de conchas, aflorantes. No leito do Córrego São João encontra-se uma fina camada de areia fina argilosa com detritos vegetais, cinza-escura, que se sobrepõe diretamente ao material argiloso cinza-azulado.

Nos locais mais distantes da costa, com lâminas de água de até $5 \mathrm{~m}$, a sequiência perfurada é bem homogênea em todos os locais, sendo constituída por material argilo-siltoso com poucos fragmentos de conchas, muito mole, de coloração cinza-azulada, podendo alcançar até $30 \mathrm{~m}$ de espessura no corpo principal; na base, a coloração torna-se mais escura, com restos de vegetais, estando presente, em alguns locais, uma fácies de areia argilosa com até $2 \mathrm{~m}$ de espessura, que passa lateralmente para material argilo-siltoso, cinza-azulado. Esta camada arenosa pode ser considerada como derivada da alteração das rochas da Formação Ilhas, no fundo. Falta, portanto, na seqüência, material bem grosseiro que viesse a atestar a presença de depósitos fluviais, devendo toda a sequiência ser considerada como marinha, tendo em vista a presença extensiva de organismos marinhos.

CONClUsóns A Baía de Aratu, de maneira geral, pode ser considerada como um ambiente de fraca energia, águas calmas. Na zona do canal observa-se uma energia um pouco maior, notadamente na Ponta da Laje. No interior da baía as ondas são muito fracas devido aos ventos serem de baixa velocidade (máxima de $4 \mathrm{~m} / \mathrm{s}$ ). As correntes criadas pelo fluxo dos rios são também bastante fracas. Desse modo, a energia que mais pode influir sobre a distribuição e a deposição dos materiais está ligada à ação das marés, sob o efeito do fluxo e refluxo através do canal.

No corpo principal, a predominância de material argilo-siltoso com áreas marcadamente argilosas (Figs. 4 e 6) evidencia uma área de fraca energia, com águas calmas. A despeito da área ser protegida da ação de grandes ondas e correntes, depósitos grosseiros são encontrados (Figs. 4, 7 e 8). Na maioria dos casos são acumulações de conchas e frag. mentos esqueletais que se podem considerar como formados no local, sofrendo unicamente um pequeno transporte, de tal maneira que śeus tamanhos têm pouca relação com a ação de correntes e de ondas. Nas desembocaduras dos rios do Macaco e Cotegipe e do Córrego 
São João, esses depósitos grosseiros são representados por grãos de quartzo, devendo estar relacionados a antigos depósitos fluviais do quaternário, posto que esses cursos de água, atualmente, não têm competência para trazer e acumular material arenoso grosseiro. Nas bordas da baía e nas zonas das coroas, quando não relacionadas a depósitos conchíferos, a existência de tipos texturais mais grosseiros, como areia-argilosa, areia-siltosa ou silte-argiloso (Fig. 4), pode estar relacionada a uma moderada ação do winnowing (joeiramento) exercida pela maré e pelas ondas, como sugerida pelo relativo bom selecionamento da população por saltação de areia fina a silte grosseiro, nas curvas granulométricas do grupo II (Fig. 5).

Na zona do canal e na área externa, os teores de material granulometricamente fino são ainda elevados, diminuindo as porcentagens de argila (Fig. 6) a partir do corpo prin. cipal até a Ponta da Laje, aumentando, dá, até a área externa. A zona da Ponta da Laje reflete a existência de uma energia mais forte, pelos baixos teores de argila aí encontrados. Esta zona de maior energia corresponde a um estreitamento do canal, com paredes abruptas, onde as correntes hidráulicas devem aumentar de velocidade.

Um aspecto a ser considerado no aprisionamento e acumulação de material fino argilo-siltoso na desembocadura dos cursos de água e nas bordas do canal, sujeitos à ação de correntes, é a existência de arbustos, gramíneas marinhas e algas verdes macroscópicas nos mangues. Scoffin (1970) observa que esses vegetais têm o poder de reduzir o fluxo da água na interface sedimento-água, permitindo a acumulação de material fino misturado com material grosseiro.

A reconstrução da evolução da Baía de Aratu durante o Quaternário é um problema que envolve o estudo de toda a Baía de Todos os Santos e da orla oceânica. Será apresentada em seguida uma tentativa de reconstrução limitada unicamente à Baía de Aratu, considerando os dados atualmente disponíveis. Estudos mais amplos pretende-se realizar num futuro próximo.

Podem ser consideradas duas grandes fases, bem distintas, caracterizadas por um episódio transgressivo seguido de um regressivo.

1. Fase transgressiva $\mathrm{O}$ mar penetrou dentro da baía, que já possuía uma morfologia própria preexistente. A transgressão foi um fenômeno geral, estendendo-se por toda a Baía de Todos os Santos, sendo responsável pela existência de numerosas ilhas e enseadas. Nessa fase, o mar alcançou um nível superior ao atual, como se atesta pela presença de depósitos conchíferos e argila azulada com conchas, próximo à Fábrica de Cimento Aratu, na cota de 2,83 $\mathrm{m}$ acima do nível médio do mar atual, como também considerando os vários terraços existentes, que chegam até essa cota. Com o avanço do mar, iniciou-se uma sedimentação argilo-siltosa, principalmente no corpo principal, que permaneceu uniforme até os dias atuais. Próximo ao fim dessa fase, iniciou-se a formação dos depósitos conchíferos, que foram crescendo a partir da profundidade atual de $10 \mathrm{~m}$, acompanhando a topografia das bordas, de um modo contínuo, à medida que o nível do mar ia subindo. Provavelmente o início do desenvolvimento dos depósitos conchíferos deve estar relacionado com variaçбes climáticas. Os atuais rios eram inexistentes ou muito incipientes.

2. Fase regressiva Recuo gradativo do mar até o nível atual. Desenvolvimento dos rios e início do transporte de materiais arenosos que se depositaram até a frente das atuais desembocaduras. Nesta fase, provavelmente, a enseada do vilarejo de Matoim (Fig. 1), em particular, foi submetida às ações erosivas das vagas e marés, criando um sistema de coroas e acumulaçóes de areia; ao mesmo tempo, os depósitos conchíferos chegaram quase ao nível do mar atual, sendo retrabalhados e reacumulados próximos às coroas, com a 
parcial eliminação dos finos. O depósito conchífero existente na profundidade de $30 \mathrm{~m}$ defronte à Ponta da Laje (Fig. 2) pode ter duas origens diferentes: (a) ou se trata de material originado no próprio local, constituindo-se num depósito independente dos demais, menos profundo ou (b) de material anteriormente acumulado em águas rasas nas bordas abruptas do canal e, posteriormente, nesta fase, erodidas e carregadas para as partes profundas do canal. $\mathrm{Na}$ parte central do corpo da baía não existem evidências deste movimento regressivo, sendo a seqüência encontrada nos poços; muito homogênea. A presença de minerais autigênicos nos sedimentos superficiais do fundo atual indica que na fase regressiva, como atualmente, a sedimentação foi bastante lenta.

Concluindo, na Baía de Aratu têm-se evidências de somente uma fase transgressiva, que atingiu o nível de aproximadamente $3 \mathrm{~m}$ acima do nível do mar atual. Este episódio transgressivo deve ser considerado como a primeira submergência do Quaternário dentro da baía, como se atesta pelos poços perfurados que mostram, sempre, um contato direto entre sedimentos cretáceos e do Quaternário, sem evidências de depósitos intermediários. A presença de materiais cinza-azulados com conchas, aflorantes nas planícies marginais dos rios, indicam a origem bem recente dessas planícies.

Considerando o problema do enquadramento das fases transgressiva e regressiva apontadas na Baía de Aratu, na evolução do Quaternário na costa do Brasil, deve-se levar em conta que as mesmas se referem aos últimos episódios do Quaternário, correspondentes à transgressão Flandriana. Com a inexistência de datação absoluta tanto na Baía de Aratu quanto na orla oceânica, o único critério para definir mais aproximadamente a posição desses eventos é o de se considerarem as flutuações do nível do mar durante a última parte do Quaternário. Bigarella (1964), no sul do Brasil, relacionou a curva das oscilações do nível do mar desde o Flandriano até os dias atuais, com os vários terraços correspondentes, mencionando, após o máximo de transgressão Flandriana (6000-5000 anos), a existência de três principais flutuações positivas com intensidades decrescentes até o nível atual. Comparando os dados da Baía de Aratu com a reconstrução apresentada por Bigarella, a correlação mais aparente, levando-se em conta a altura dos terraços e a grande espessura dos sedimentos na Baía de Aratu, é com a fase por ele chamada de "Submergência Cananeiense", entre $4200-3500$ anos, aproximadamente.

Tricart e Cardoso da Silva (1968) fizeram uma reconstrução do Quaternário na orla oceânica de Salvador baseando-se em critérios morfoclimáticos. Os citados autores consideram a transgressão Flandriana como a última fase do Quaternário, atingindo um nível máximo de $1 \mathrm{~m}$ acima do atual, no Dunquerquiano (arenitos de praias e restringas), sem mencionarem as flutuações pós-Flandrianas apontadas por Bigarella (1964). Este nível é mais baixo que o encontrado na Baía de Aratu $(2,83 \mathrm{~m})$, podendo essa diferença ou estar relacionada a pequenos movimentos epirogenéticos locais ou a correspondências distintas, entre os dois diferentes níveis mencionados, com diferentes níveis de flutuação pos-Flandrianas apresentados por Bigarella.

Agradecimentos Os autores agradecem à Profa. Yeda de Andrade Ferreira, executora do "Projeto Geofísica do Fundo do Mar e Sedimentos Recentes da Baía de Todos os Santos", pelo estímulo e dedicação dispensados durante todas as fases do trabalho; ao Prof. Shiguemi Fujimori, pelas sugestőes apresentadas; e às entidades financiadoras, Universidade Federal da Bahia, Conselho Nacional de Pesquisas e Ministério do Planejamento.

\section{BIBLIOGRAFIA}

Aratu, O Centro Industrial de - 1967 - Plano Diretor, Empreendimento da Bahia, S. A., Salvador, 2 BIGARELLA, J.J. - 1964 - Variaçz̃es climáticas no quaternário e suas implicações no revestimento florístico do Paraná, Bol. Paranaense de Geogr., 10-15: 211-231 
BITTENCOURT, A. C.S. P., NERY LEÃO, Z. M., BRICHTA, A. e DI NAPOLI, E. - Uma ocorrência de chamosita nos sedimentos recentes da baía de Aratu, Bahia, Est. Sedịmentol (no prelo)

EMERY, K. O. - 1952 - Continental shelf sediments of southern California, Geol. Soc. America Bull., 63: 1 105-1 108

EMERY, K. O. - 1965 - Geology of the continental margin off eastern United States. In: W. F. Whittard and R. Bradshaw (Editors), Submarine Geology Geophysics. Butterworth, London, pp. $1-20$

EMERY, K. O. - 1968 - Relict sediments on continental shelves of the world, Am. Assoc. Petroleum Geologists Bull., 52: 445 464

EMERY, K. O. e STEVENSON, R. E. - 1957 - Estuaries and Lagoons, I. Physical and Chemical Characteristics, Geol. Soc. America, Mem. 67, 1: 673-693

KUTNER, A.S. - 1962 - Granulometria dos sedimentos de fundo da região de Cananéia, S.P., Bol. Soc. Bras. Geol., 11 (2): 41.54

MABESOONE, J. M. - 1971 - Fácies sedimentares da plataforma continental brasileira, Est. Sedimentol., 1 (1): $55-71$

MABESOONE, J. M. e COUTINHO, P. N. - 1970 - Littoral and shallow marine Geology of northern and northeastern Brazil, Trab. Oceanogr., Univ. Fed. Pernambuco, 12: 1-214

MARLOWE, J.I. - 1968 - Unconsolidated marine sediments in Baffin Bay, Journ. Sed. Pet., 38: $1065-1078$

PASSEGA, R, RIZZINI, A. e BORGHETTI, G. - 1967 - Transport of sediments by waves, Adriatic coastal shelf, Italy, Am. Assoc. Petroleum Geologists Bull., 51: 1 304-1 319

PEIXINHO, V. M. G. - 1972 - Estudos preliminares sobre o fitoplâncton da baía de Aratu. Memória apresentada ao Depto. de Bọtânica do Instituto de Biociências da Universidade de São Paulo para obtenção do grau de Mestre em Botânica (mimeografada), 81 pp.

PORRENGA, D.H. - 1967 - Glauconite and chamosite as depth indicators in the marine environment, Mar. Geol., 5: 495-501

SCOFFIN, T.P. $-1970-$ The trapping and binding of subtidal carbonate sediments by marine vegetation in Bimini lagoon, Bahamas, Journ. Sed. Pet., 40: 249-273

SELLWOOD, B. W. - 1971 - The genesis of some sideritic beds in the Yorkshire Lias (England), Journ. Sed. Pet., $41: 854-857$

SHEPARD, F. P. - 1954 - Nomenclature based on sand-silt-clay ratio, Journ. Sed. Pet., 24: $151-158$

SHEPARD, F.P. e MOORE, D. G. - 1954 - Sedimentary environments differentiated by coarse - fraction studies, Am. Assoc. Petroleum Geologists Bull. 38: $1792-1802$

SHEPARD, F. P. e MOORE, D. G. - 1955 - Central Texas coast sedimentation: Characteristics of sedimentary environment, recent history, and diagenesis, Am. Assoc. Petroleum Geologists Bull., 39: 1 463-1 593

SWIFT, D. J. P. - 1970 - Quaternary shelves and the return to grade, Mar. Geol., 8: 5-30

TRICART, J. e GARDOSO DA SILVA, T. - 1968 - Estudos de Geomorfologia da Bahia e Sergipe, Pub. da Fundação para o Desenvolvimento da Ciência, 167 pp. 